\section{OP-23 UNDERSTANDING THE DISTRICT PLANNING PROCESS FROM THE PERCEPTIONS OF STAKEHOLDERS IN THE DISTRICT HEALTH SYSTEM UNDER THE NATIONAL RURAL HEALTH MISSION}

Neha Adsul. TISS - Tata Institute of Social Sciences, Mumbai (Maharashtra), India

\subsection{6/bmjgh-2016-EPHPabstracts.23}

Background Nearly three decades ago, the WHO report 'The challenge of implementation: district health systems for primary care' defined a district health system (DHS) as a decentralised unit and building block of national health system, and a means to achieve an equitable and responsive health system. A DHS being more than an organisation ideally is the manifestation of comprehensive health service delivery through the process of community participation and bottom-up planning and management. Decentralised planning is seen as a positive step for efficient and effective use of resource and for needs-driven planning.

In India, the National Rural Health Mission in its 2005 Mission Document adhered to this vision and wanted districts to become the 'core unit of planning, budgeting and implementation'.

The present research seeks to understand how the DHS stakeholders in India today perceive their role of being involved in the district planning process in the light of three important areas namely (1) awareness about the importance of the district planning process; (2) their role in the district planning process; and (3) the major problems encountered by them while planning for the district.

Methods We applied a qualitative exploratory research design situated in a constructivist paradigm. Primary data consisted of in-depth interviews with selected participants following a guided schedule. Secondary data consisted of the available District Health Action Plans. The unit of analysis was the District Programme Management Unit (DPMU) and its support system at block level (BPMUs) under the selected district ' $\mathrm{X}$ ' of Maharashtra. The study population consisted of: (a) at the level of the district: the District Programme Manager (DPM), the District Accounts Manager, the District Data Entry Operator and the District Health Officer (DHO); (b) at the level of each block: the Block Programme Manager (BPM)/Taluk Health Officer (THO), the Block Accounts Manager and the Block Data Entry Operator. All mentioned district and block level officials as well as NRHM support staff at district and block level, willing to share their experience, were considered for being interviewed. In total, 19 DHS stakeholder were interviewed, covering all six blocks under district ' $\mathrm{X}$ '. Using ATLAS.ti version 6.1 software, descriptive and analytical coding were completed successively.

Findings The study revealed that planning was mainly seen as a process for procuring funds for the district and respective blocks. One BPM formulated it this way: "Budget, budget! (smiles) Paisa! [Money] How do you think we keep the work going in the district? (laughs) It's only after we send the District Health Action Plan from our side, that the people at the district will give us money to spend. Otherwise gone (smiles)". Another BPM: "So, we have to follow all these steps and then only they release the budget for the block". Almost all the interviewed $\mathrm{BPMs} / \mathrm{THOs}$ considered the planning process as a mechanism to acquire "budget [funds]" for their respective blocks.

The planning process is yet to be perceived as a tool to design a needs-driven document, i.e. a District Health Action Plan that represent the local and priority needs of the respective blocks. A majority of BPMs/THOs described the planning process as "compiling" the information filled up in "formats" or "data sheets" received from higher level and sending it back, even if some of them used the term "bottom-up planning" for the described process. No genuine communication or consultation seemed to be part of this process.

District planning was perceived as a process of "consolidating" filled-up formats of the action plans and "reporting" again to higher levels by almost all the Accounts Managers and Data Entry Operators, considering these steps of uttermost importance in the planning process.

In practice, the blocks appear to draw up plans by taking previous year's figures and adding a percentage, leaving no space for any major amendments to be reflected through the planning process. As one Accounts Manager described it, "Each year we add about $10 \%$ more to the budgetary amount that we had proposed for the previous financial year and accordingly we submit the block plan to the district (...) then (...) at the district those people consolidate all the block plans and submit them to the state level (pause) accordingly, we receive the funds then".

As per the accounts of the District Accounts Managers and District Data Entry Operators however, the District Health Action Plan is not the primary basis for allocating funds to the districts. This deviation from the norm has origins in inputs and process. At the input level, the data provided at lower tiers leave much to desire. As one DEO expressed it, "I have jotted down all their mistakes of the previous formats, Then, I call them and ask them to resubmit the corrected figures. All this is extremely time consuming and probably they are so much reluctant to work that they keep repeating the same mistakes over and over again". At the process level, the common practice appears to be a one-size-fits-all approach: a majority of study respondents indicated that allocation to the blocks was not based upon the demands generated through the Block Health Action Plans (BHAPs), but rather consisted of a somewhat mechanical distribution of almost equal funds irrespective of the variation in needs. According to one Accounts Manager, "We mostly don't receive the budget that actually we had proposed (...) we actually receive less than what we proposed, So it feels as if there is very little that we can do about planning”. A BPM sums it up: "DHO and other seniors say that it is sometimes our fault also that we commit some errors while planning and all (pause) I don't know exactly (pause) Sometimes it is that the budget is released from the Centre so they might have some of their own problems also. Now who goes to ask then as why they are allocating less budget to us?".

Discussion \& conclusion For bottom-up planning to be functional, inputs are taken from village plans in order to design block plans and in turn, district plans take the inputs provided from block plans. This process requires consultation and active involvement of relevant stakeholders at all levels of the local health system. However, the qualitative data collected suggest that consultation is largely absent from the planning process as practiced today. A major reason for this lack of communication can be accounted to the fact that the stakeholders involved regard planning merely as a programmatic compilation exercise. Reporting and meeting timelines is seen as more important than the quality of the plans produced. As a result, actual planning is highly inefficient, leads to frustration among all actors, to distribution of funds irrespective of needs, and to weak and inequitable local health systems.

For the bottom-up planning as envisioned in NRHM to become reality, for local health systems to become stronger and 
for effective contribution to health equity, there is an urgent need to empower all actors at district level and below, and to encourage and support dialogue and consultation at all sublevels so as to build managerial capacity for improved block and district planning.

No competing interest. 